\title{
On the Transformation and Popularity of the Cheongsam in Modern Time
}

\author{
Ying Ding \\ Jiangxi Institute of Fashion Technology, Department of Dress Design and Engineering \\ Jiangxi Institute of Fashion Technology, JF \\ Nanchang, Jiangxi \\ E-mail: 185503378@qq.com
}

Keywords: Cheongsam; The Status of the Development; The Popularity; Design; A Combination of Western and Eastern Elements

\begin{abstract}
For thousands of years, all the Chinese women dresses were made through the straight cutting in tailoring. The bosom, the shoulder, the waist and the buttocks of the clothes were all straight. The women's line of beauty didn't show completely at all. As far as the cheongsam, the characters were also kept. After the Revolution of 1911, the Chinese women started to understand what the line of beauty under the effect of the western economical culture is. After that, the cheongsam was improved and recreated from the insignificant tailors to the famous designers, showing the women's line of beauty exhaustively. Nowadays, the cheongsam which play an important role in women's life has become a culture. Comparing and researching the change of modeling and the character of structure of the cheongsam of different periods, which will have very important significance towards how to keep and expand the traditional national culture and understand the popular trend of the cheongsam.

The name of the cheongsam could be traced back to the beginning of the Qing dynasty. Dragon required all the sons of China to wear the robes when they entered the Shanhaiguan, which was also called the cheongsam of the Manzu. (As shown in Fig. 1) Literally, the cheongsam meant the robes which were worn by the sons of China. In the origin, it didn't distinguish the male and the female. Afterwards, the common girls who didn't enter the Shanhaiguan including the female of Han nationality all imitated the wearing climate of Man nationality. And it became more and more popular among the rich women. The decoration of the cheongsam of the Mao women was famous for their complexity. However, as for the modeling, the way of straight cutting was made. After the Revolution of 1911, the people's ideas had changed, so the traditional clothes were experiencing potential changes, and the cheongsam was affected by the western culture.
\end{abstract}




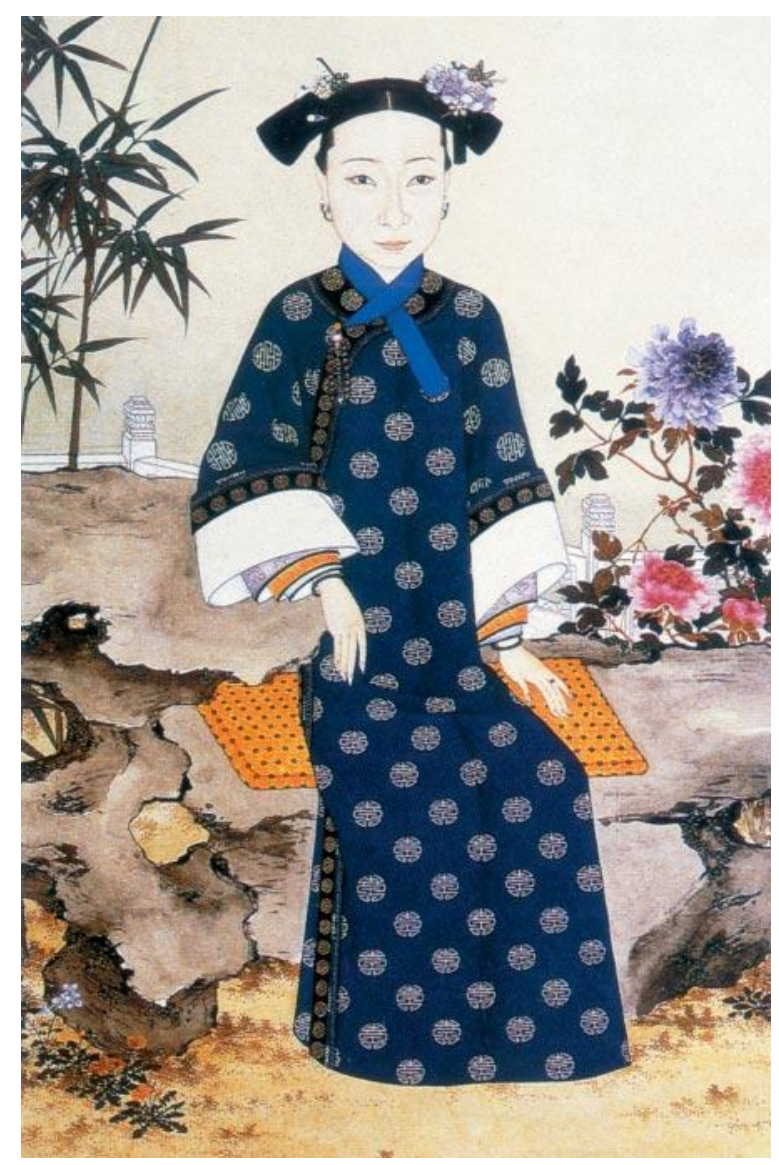

Figure 1. The manchu cheongsam

After the revolution of 1911, the feudal rule of Man and Qing dynasty was overturned, and the clothes lost the position of symbolizing the status and hierarchical, which developed towards the plebification and the free international change direction. Therefore, many changes happened to the cheongsam. At the beginning of 20st, China's political were turbulent. During the twentieth of 20st, new civilization clothes were very popular among metropolis female. In the year of 1912, the women wore the robe. After Mao's entering, the cheongsam had the same status with other clothes, mutual nonaggression. The women of the Man thought that their robes were short of beauty of women, and wanted to wear enchanting pants. However, it was forbidden strictly by the emperor. After the idea of Five Nationality Unity for a Republic, all women wore the cheongsam coinciding, which was not loyal to Man and Qing dynasty and advocate the restoration movement, but for the reason that the women wanted to imitate the men deliberately. The women at this time were affected by the western culture edification, addicting to the equal right between the man and the woman. However, the real situation was thoroughly different from the desired situation. Under the ashamed and resentful situation, they refused everything which belonged to the women, and wanted to discard what used to be owned by the women. Just at this time, the western culture were introduced to China, the Chinese women began to enjoy the line of beauty. And just at this time, the cheongsam was improved and recreated from the insignificant tailors to the famous designers, showing the women's line of beauty exhaustively. Tug-of-war between west and east were applied into the cheongsam.

In the twenties of 20th, the cheongsam were very popular among the women under the effect of the western clothes. The kind of cheongsam was accepted by people after the Han recreated according to the style of the western clothes when they were introduced into China. The common front of the cheongsam contains meaning front, lute front, slant front and double front; the collar contains high collar, low collar; clip cheongsam; single cheongsam. The cheongsam of the thirties of 20th has has become the criterion of Chinese women. At this time the transition of clothes of has arrived Shanghai. Shanghai is the very important town of pursing for the revolution. The missionary, the merchant and the people who agreed for the revolution competed for women studying. And the wave of the tide 
pursuing for the revolution of women liberation, pursuing for simplify and concise. The cheongsam began at the beginning at the start of horse waistcoat. After that, the horse waistcoat was changed into the style of the model of sleeve, and this becomes the new start of new style of the cheongsam. However, the students of Shanghai have become the starters of the popularity of women students in Shanghai. The represent of shanghai in that time of women, has become the idea image of the society of that time. They are the leaders of the women, the culture and the fashion. Of course, they become the model of many students of modeling Shang students. The recreated cheongsam appeared in the 30s of the 20th. The cutting and the structure of the cheongsam's cutting was very western, the place of breast and waist was suitable to the body, just at this time, the shoulder and the decoration sleeve as starting, which made the cheongsam suitable for the body. It was the body of what we called beauty body. Of course, it is the effect of women effect of women army women fashion. This showed that man and women discarded heat the show of shoulder is the ideal in their press-ion. The change in cutting and structure was completed in Shanghai. As you know, the cheongsam of this time was decided, and the cheongsam of the 30s of 20th could not avoid the model in the 30s of 20th. There were some changes in long and short criterion and fat and thin and decorations. (As shown in Fig. 2)

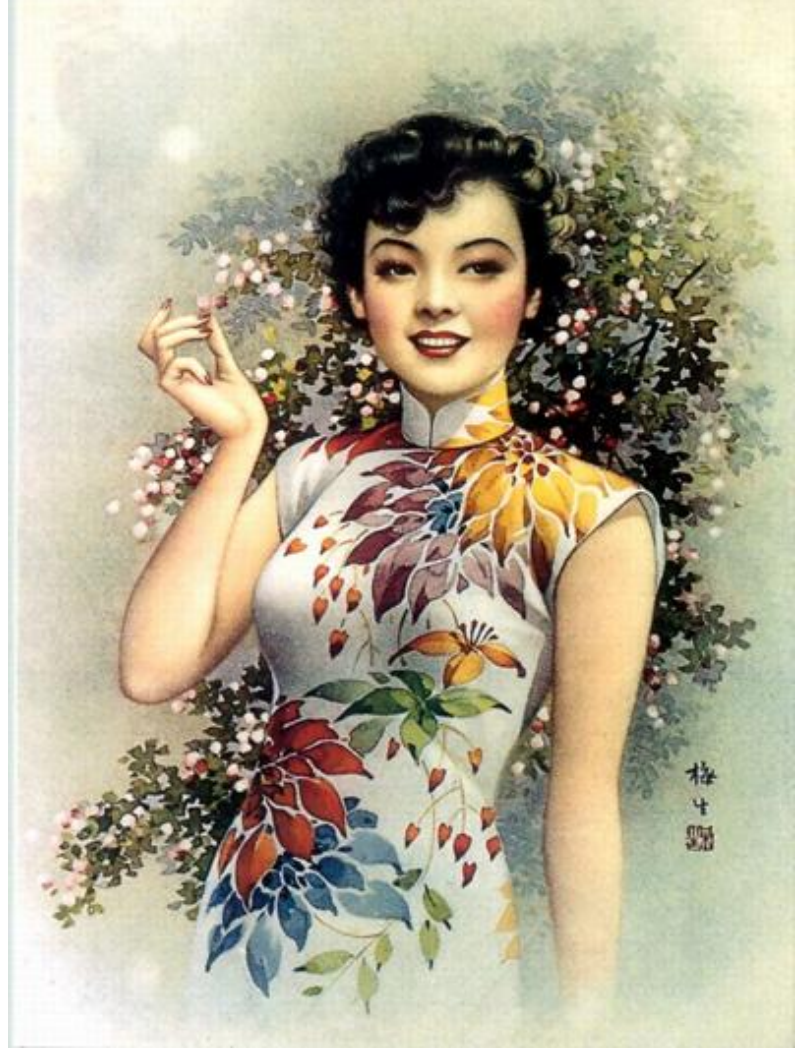

Figure 2. Chinese dress

The writer Zhang Ailing has said that the preliminary cheongsam was round collar and upright, had the characters of puritan. Until the thirties of 20th, the recreated cheongsam nearly had become the standard clothes for all the women. The classic cheongsam of twenties of 20th was the overseas dress which was known by everyone, and the cheongsam was owned by every rich and loyal woman in that time. Of course, this period was called the Golden Age of the cheongsam. China had its own real fashion clothes just at this time. The overseas cheongsam melt the characters of western clothes culture were sweeping the country from Shanghai. As the classic design sample of the cheongsam of all the country, there was an old saying about the cheongsam that everyone learned the way of Shanghai women's wearing, but none of them looked like, and Shanghai's women had their new style when they imitated three tenth. All of these have proved that the cheongsam of Shanghai had become the model of the women of the country. (As shown in Fig. 3) 


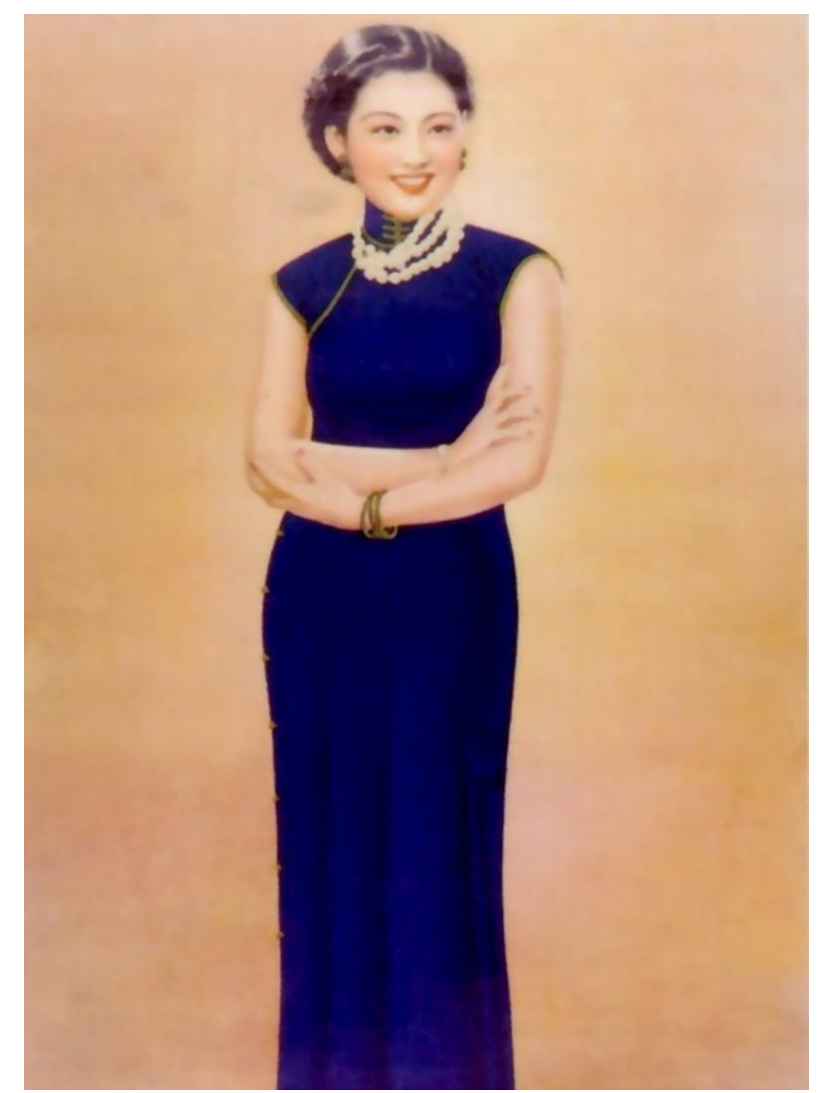

Figure 3. Chinese dress

During the time from the fifties to the before of the reform and opening, the cheongsam was called the Four Olds (old culture, old ideas, old customs and old habits). The cheongsam was also called the production of feudalism, capitalism and revisionism. Until the birth of the policy of reform and opening, the cheongsam was accepted by the women. The color of the cheongsam was just limited in black, gray and blue before reform and opening up. After that, the color of the cheongsam was more rich and various. There's no doubt that the cheongsam which disappeared for almost 30 years were worn by the women who liked to pursuit the beauty. However, for the vocational women, to wear the cheongsam was not convenient and suitable considering going out, doing work and household labor. Especially entering the information time, the women in China had their own beauty value, and the cheongsam could show the beauty of the women. And the cheongsam made them looked like round as pearls and smooth as jade. Of course, there were many styles for women to choose. At the time of 80s and 90s of 20th, a uniform cheongsam which symbolized the vocation of wearing the cheongsam appeared in China. The waitresses in hotel and other amusement halls wore the cheongsam. Terribly, the cheongsam was formulaic, flirting in color, high vents in the leg or the breast even in the back. The material price was inexpensive, the sewing was unevenness. All damaged the perfect status of the cheongsam to the people.

With the development of the fashion clothes, many designers pursuit the design inspiration from the classic traditional clothes, and the cheongsam becomes one of the sources of design inspiration. The fashion design added the innovation consciousness to the cheongsam. First, the innovation was the color. Pure red or pure purple, deep red and golden silver were all used usually by the traditional cheongsam. In modern society, the designer could design different color cheongsam according to the need of the consumers. Especially with the development of digital technology, digital printing was also applied to the color of the cheongsam by the designer. Several years ago, gradient color was very popular among the designers. Therefore, the color of the cheongsam is very rich. Second, the innovation was the style. Only the innovation in style and adding new elements, the cheongsam could find its place and attract people's attention. Of course, the change in style focused on the collar, body, sleeve and slitting. Third, the innovation was in material and pattern. Different materials could be 
made into different cheongsam. The common materials contained real silk and tapestry stain. Nowadays, the cotton and the pleuche were made into the cheongsam, and it was not bad. The combination of the cotton and the wool, the knitting material and the tatting material, the silk and the leather, the non woven material and knitting material all made the cheongsam shine new color. The innovation cheongsam could show the temperament of the women through the different patterns and stripes. Especially after the appearing of digital printing, we have many ways to choose the unique material and distinct \&artistic patterns, reaching the designer needs of printing the pattern of what they wanted. In the end, the innovation was the accessory. The traditional buttons could classify into the plate buttons and weave buttons. With the creation of the designer, the design of the button was improving day after day. A new button which was filled with dragon bone through the traditional craft was very popular among the women who love to wear the cheongsam due to its cubic of vision effects. Besides, pearl, jewel, rosewood, marble, turquoise, lazurite, crystal and tooth skeleton were all made into the string buttons which were gradually used by the designer which added new attention to the cheongsam. On the decoration, if you wear the Chinese clothes, the best decoration for that were ear rings, especial with the drapability. The ear rings could be made through the pearl, diamond, rubine and silver. Of course, functional fiber, recycle material and cowry material could also be considered to decorate the cheongsam. If you like, the fashion bags could also be used to decorate the cheongsam with the match of all kinds of high-heeled shoes.

In the international clothes market, the cheongsam could really show the characters of Chinese culture and took a place. However, the cheongsam could really revive only through the innovation. The innovation of cheongsam was design idea, this was the first. We should put the fashion elements into the cheongsam series design containing fabric design, style design, structure design, craft design and marketing design. In this constantly changing period, anything which never changes would be put on the shelf. The cheongsam must keep the pace with the times, meet the needs of the social and industrialize the production through the creation of the design. Only through this way, Chinese cheongsam would find its place in the world. Today, the cheongsam are disappearing gradually from our daily lives. We sometimes just can see the cheongsam on the wedding and cocktail party. As a dress, the style and the stripe are becoming more and more complicated and gorgeous. On the style, the smooth line of the cheongsam is kept. When designing and cutting, the designer made the structure precise, the line smooth. There is no any accessory such as belt, loop and bag. On the craft, embroidery, decoration with flowers and setting with pearls are used to enhance the effect of the texture. Besides, the art of drawing is also used as a decoration of the cheongsam. The cheongsam with the flowers, birds, figures and facial makeup is not only exquisite and novel, but also gentle and charm. The combination of fashion design and drawing breaks the old design idea and becomes the character in international fashion stage. Besides, the innovation of the production technology, the improving of craft process, the use of the new material all provide chance for the development if the cheongsam, we believe that the cheongsam will be loved and fashionable than ever before.

The cheongsam had the history of more than five hundred years. At that time, the women worn the cheongsam with the cap, flat shoes, and they had never thought that the cheongsam could unify all the women on some day. Under the effect that the nation is the world, most Chinese fashion designers use the traditional elements as their title on some extent. We could see the traditional vision image from the fashion design sometimes. It has nearly become the spokesman of the traditional culture. Of course, this needs the designer to innovate again and again. If we just copy the tradition without any change, our design will fall behind the time greatly. As we all know, Yohji Yamamoto, Issey Miyake and Hanae Mori are all famous Japanese designers, they are famous in the fashion circle because they combined the Japanese culture with the western fashion culture, to design the production with the character of the time. In China, a designer won the golden award through the application of the official uniform in Qing dynasty into the modern dress design in France Youth Design Race. It has proved that every village in the earth has its differences in the showing form, method and conception of the artistic; but it has the same results in the needs and implications of aesthetic. From the modern development of the cheongsam, it represented the Chinese clothes, the cheongsam focused on the essence of clothes for thousands of years. It had great relationship with its keeping and disappearing. The cheongsam kept the connotation of the traditional culture, and absorbed the idea and skill of the 
western, evolved the modern cheongsam with the characters of the western and the eastern. (As shown in Fig. 4)

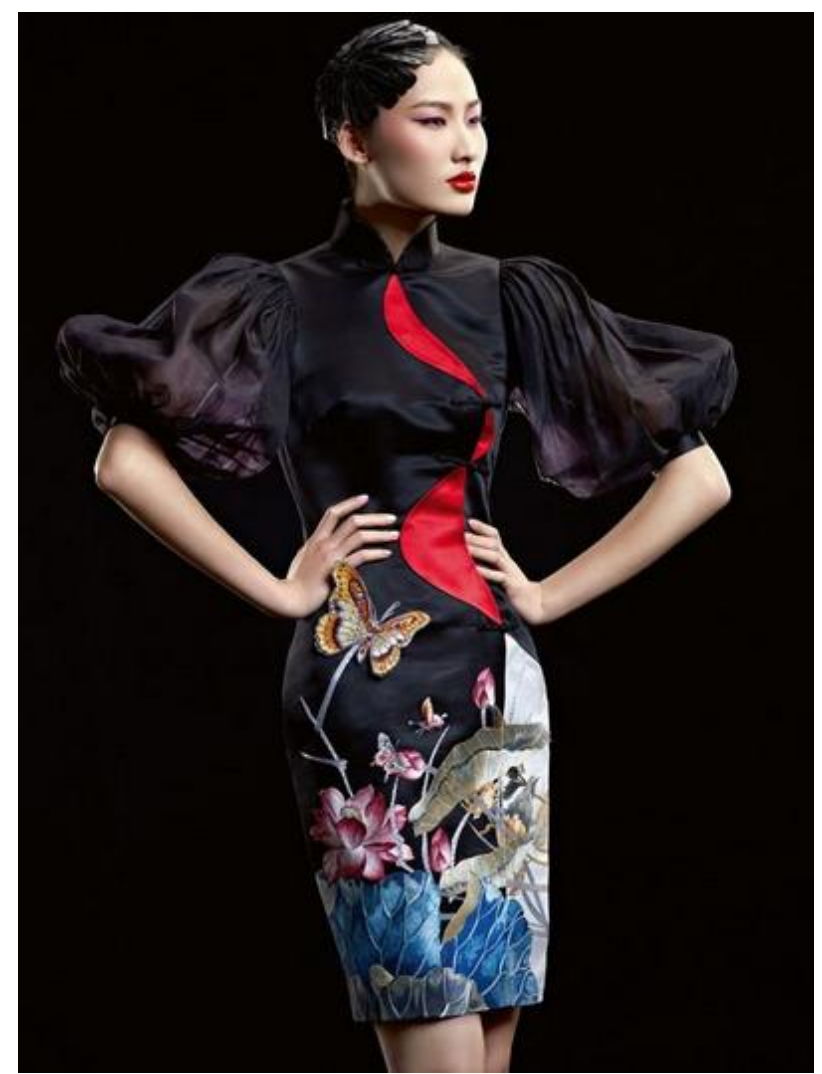

Figure 4. NE·TIGER

Foreign designers designed the unique characters with the international under the inspiration of cheongsam; even combining the Chinese cheongsam with the European evening dress. The cheongsam was called the classic clothes of the modern women, because the style showed the virtuous, the gentle, the sexual and the fresh. It could also show the women's fashion temperament and disposition. Therefore, the cheongsam was developing with the time, on one hand, it born the weight of the Chinese clothes culture and showed the habit and virtue of the women. The character line has many kinds: such as $\mathrm{H}$ form, $\mathrm{S}$ form.

The waist of the cheongsam was designed into tight to show the line of beauty. Of course, the place of breast and buttock were looser than the waist. So the model looked like $\mathrm{H}$ form. Based on the research of body ergonomic, the cheongsam made the women have full breasts and high ass, which looked like $S$ form from the side. The out-side form of the clothes was created by the famous designer from the France. In order to meet the needs of wearing, the three-dimensional cutting which was developed by the Putter. The style of the cheongsam developed towards three-dimensional model, curving cutting and showing the line of beauty from plane modeling and straight cutting, emphasizing the craft decoration. Through the compare and the research towards the characters of the style and the structure of the cheongsam in different periods, it had great value on how to keep and carry the traditional culture; it is useful to know more about the clothes culture. Only this way, the nation is the world could be showed really. The melting of the traditional culture provides more chances for modern women. The concise and the diversification had become the real fashion. We need to understand and expand the culture connotation of the cheongsam in order to keep the pure beauty. We should not ignore the change and the creation of the clothes culture when we pursue the beauty of the cheongsam, which is needed by the development of the international culture. Nowadays, many women starts worn cheongsam for many times in many occasions, and this phenomenon has become a new line of scenery. (As shown in Fig. 5 and Fig. 6) 


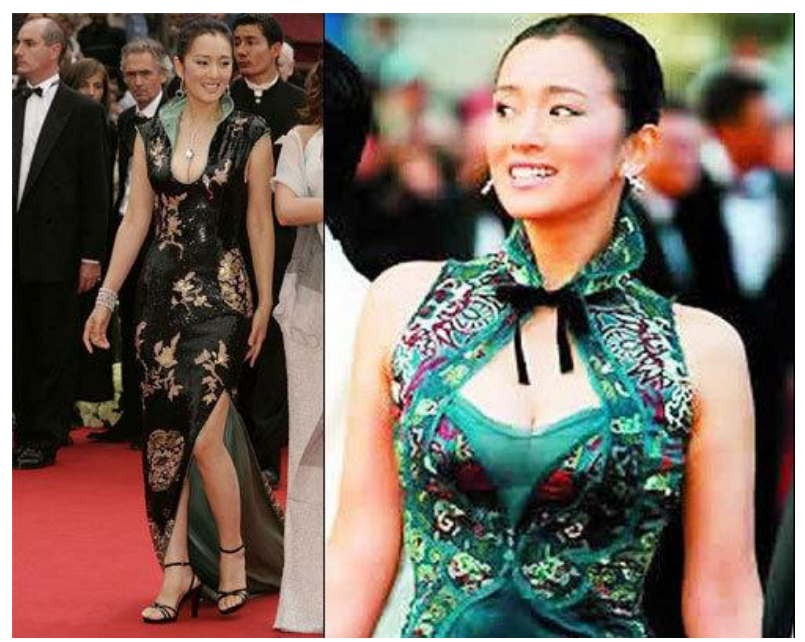

Figure 5. GongLi

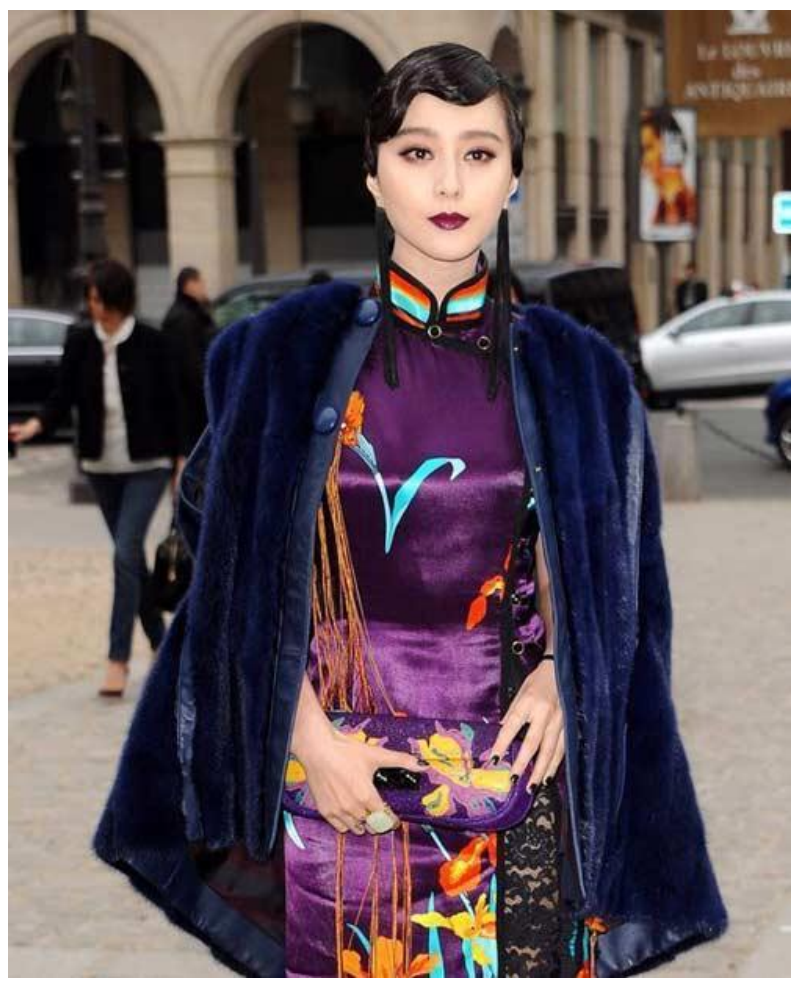

Figure 6. Fan Bingbing

We all love our country and nation, and love our culture of the nation. Until today, the cheongsam is not only a dress, but symbolization, a sign, a mark, a pride and a culture. As the brightest pearl in Chinese clothes, the cheongsam had glorious history and will have bright future.

\section{References}

[1] Hua Mei, the History of China, Tianjin people's Fine Arts Publishing House. 1994(the second edition)

[2] Yuan Ze, the History of China, China Textile and Apparel Press, the oct. 2005.

[3] The collected works of Zhang Ailing, the fourth roll, Anhui art press,1992(the first edition)

[4] Liu Yu, the Culture History of Chinese Cheongsam, Shanghai people's Fine Arts Publishing House, the july of 2011. 
[5] Jiang Yinli, on the design elements and modern application of the cheongsam in 1920S. [D] the agriculture university of Zhejiang, 2011.

[6] Teng teng, the culture meaning and the aesthetic characters of the cheongsam, [D] Shangdong university,2008.

[7] Zhao Ming, the collision and the fusion of the culture--the research on the traditional cheongsam[J], Art Design Research,2013(03)

[8] Zhang Anxun, Wang Honggang, the oversea cheongsam and women kimono[J] Financial View. 2015-03-08.

[9] Qin Ming, On the Development and Change of the Cheongsam.[J] Art View.2015-02-15.

[10] Guo Fengqiu, Huang Liyong, the application comparative analysis of the elements to the cheongsam from the designers in west and in east.[J] beauty and time.2015-02-15

[11] Chen Yunfei, the cheongsam and the debutante, the east press.2014-8-1. 